\title{
Waldisa Rússio: O Museu da Criança e as Oficinas Infantis do Museu da Indústria. A arte nos projetos de preservação do patrimônio Sophia de Oliveira Novaes ${ }^{1}$ DOI 10.20396/eha.vil4.3386
}

A pesquisa que se segue foi realizada com bolsa de auxílio da Fundação de Amparo à Pesquisa do Estado de São Paulo (FAPESP) e visa o estudo sobre a documentação da museóloga Waldisa Rússio (1935-1990), com o objetivo de identificar e estudar algumas de suas práticas que marcaram a história da educação museal brasileira. Com isto, a pesquisa realizou um conjunto de ateliês de arte e de experimentação, inspirados nas concepções de Rússio, acerca do ser e estar nos ambiente de herança cultural.

O Fundo Waldisa Rússio localizado no IEB-USP, contém cerca de vinte e cinco mil documentos da museóloga, entre eles: cartas, ofícios, revistas, livros, publicações, catálogos, anotações e reflexões que faziam parte de seu cotidiano. Doados pela mãe da autora em 1992, formam um importante conjunto de informações a respeito da museologia brasileira e de uma parte importante da formação cultural paulista da segunda metade do século XX.

Rússio formou-se em Direito pela Universidade de São Paulo em 1959, passando a atuar no campo cultural ligado ao Estado, com múltiplas funções administrativas, passando a atuar de forma definitiva na área museológica à partir da década de 70. Logo, realizou seu mestrado e doutoramento no campo, na Fundação Escola de Política e Sociologia de São Paulo (FESPSP).

A atividade docente passou a ser uma de suas principais atividades, dedicando-se ao campo cultural, atrelado à museologia na FESPSP. Foi professora de diversos nomes da atuação cultural atual, como Maria Cristina Oliveira Bruno e Marcelo Mattos Araújo. Tendo consolidado em 1978 o curso de especialização em Museologia vinculado ao Museu de Arte de São Paulo (MASP), no qual Pietro Maria Bardi apoiou Rússio. Posteriormente o curso passou a ser vinculado ao Instituto de Museologia na FESPSP, tendo funcionado até 1996.

A professora e museóloga Waldisa Rússio foi uma das personalidades centrais, no Brasil e fora dele, para o estabelecimento das bases do pensamento museológico contemporâneo. Waldisa coordenou diversos projetos e implantação de museus estaduais entre o final da

1 Graduanda em Têxtil e Moda na Universidade de São Paulo-USP. Fundação de Amparo à Pesquisa do Estado de São Paulo-FAPESP. 
década de 1960 e durante toda a década de 1970. No final da mesma década, foi a principal responsável pela constituição do primeiro curso de pós-graduação em Museologia do país, iniciado em 1978 na Fundação Escola de Sociologia e Política de São Paulo. Desse modo, contribuiu decisivamente para a consolidação da área profissional no país, ao colaborar para o desenvolvimento de uma discussão acadêmica sobre Museologia. ${ }^{2}$

Lutou pela regulamentação da profissão museólogo e fundou órgãos que auxiliavam a classe. O patrimônio foi o objeto de estudo para a museóloga, estando à frente de diversos projetos nacionais, e em outros de perspectivas internacionais. Destacou-se na estruturação do Museu de Arte Sacra de São Paulo, Estação Ciência e Museu da Casa Brasileira, tendo desenvolvido trabalhos museológicos no Museu do Bixiga e Casa Guilherme de Almeida. Chegou a vislumbrar e planejar o Museu da Indústria para São Paulo e o Museu da Criança, que segundo a documentação, foi estudado para ter também uma sede em Portugal, junto a Fundação Calouste Gulbenkian.

A pesquisa dedicou-se a estudar as atividades desenvolvidas especificamente nas Oficinas Infantis do Museu da Indústria e ao projeto de Museu da Criança, a fim de investigar o olhar sensível que Rússio propunha à experimentação com arte nos museus.

Waldisa Rússio acreditava que a base do museu era o homem e a vida. Os museólogos seriam trabalhadores sociais, de maneira que o espaço do museu necessitava ser interdisciplinar e comprometido com uma ação educativa cultural. Neste sentido, desenvolveu o famoso termo "fato museal", que descrevia como: "O fato museológico é a relação profunda entre o homem - sujeito conhecedor -, e o objeto, parte da realidade sobre a qual o homem igualmente atua e pode agir."3 (1981), de forma que os museus seriam possibilidades de encontro para trocas e vivências que valorizam o passado, ao passo que são presente e futuro, pois podem produzir matéria humana de seu próprio tempo.

O texto "Os Museus e A Criança Brasileira", publicado em 1979 em O Estado de São Paulo, disserta a respeito da condição de recepção das crianças nos museus brasileiros. Rússio critica a falta de programas que possam receber crianças menores do que 10 anos e que não estejam acompanhadas de seus pais, afirmando que a criança brasileira não só é esquecida pelos museus, como também é banida.

Do pequenino Portugal ao novíssimo Israel e aos superpoderosos Estados Unidos, é inacreditável o número de crianças que não apenas visitam, mas participam de atividades

\footnotetext{
2 MATARAZZO, 2010 p. 15 in BRUNO, 2010

3 Documento consultado no Fundo Waldisa Rússio do IEB USP em 2018.
} 
especiais dos museus. [...]Por tudo isso me parece imperdoável que os museus brasileiros não tenham sido despertados para a necessidade de serem algo mais que um resíduo arqueológico do ensino, meros complementos da educação formal. [..] é inacreditável, quando se sabe que a pirâmide demográfica brasileira repousa sobre a larga base de jovens e crianças. ${ }^{4}$

Desta maneira, a autora esboça algumas recomendações para um esforço mútuo entre os educadores e os trabalhadores de museus. A primeira diz respeito a importância de um espaço dedicado a criança, que seja integrado à exposição e as demais atividades do museu; e a segunda, trata sobre a necessidade dos programas não deixarem a criança como sujeito passivo, sendo preciso que se elabore mecanismos que permitam a autoexpressão e o uso da liberdade sem interferências.

Liberta, participante e ativa, respeitada, a criança passa a amar e respeitar o espaço que a recebe e a abriga, no qual convive com os objetos; não os danifica, convive com eles. Sobretudo, é preciso que os museus repensem a sua função como efetivamente humanizadora. ${ }^{5}$

À partir dessas concepções é importante analisar como Waldisa elabora estratégias práticas para a recepção da criança no espaço museal. Um dos exemplos mais significativos é a proposta para o Museu da Criança (1983), que também teve uma versão pensada em parceria com a Fundação Calouste Gulbenkian, de Portugal. Nessa proposta, Rússio afirma que lhe agrada muito o termo "criança" como um ser que está se criando, se fazendo e se constituindo.

Destaca que a criança na fase da pré-escola - entre os 3 e 4 anos - que ainda não faz parte do grupo escolar, deveria ser uma das prioridades no atendimento. Rússio acredita que o museu seria benéfico para esta faixa etária, pois ajudaria em seu processo de reconhecimento do mundo, na construção de símbolos e imagens e no desenvolvimento da inteligência e do caráter. Para a autora, se esses estímulos à consciência tivessem sido aprimorados, não teríamos processos de urbanização, modernização e produção de maneiras tão caóticas.

Na proposta, os Centros infantis e os Museus de(a) Criança de locais como Índia, França, Jerusalém e Nova York são citados por carregarem um intuito semelhante, porém Rússio escreve que seu projeto seria inovador no que tange os objetos fixados, a metodologia de trabalho e a natureza do acervo museológico.

O acervo museológico seria constituído a partir de uma "Tríplice Natureza". Nele, haveriam objetos ligados ao universo infantil, como os tradicionais brinquedos, reunidos pela própria equipe

\footnotetext{
4 Arquivo IEB - USP, Fundo Waldisa Rússio, sem código de referência. RÚSSIO, 1979

5 Arquivo IEB - USP, Fundo Waldisa Rússio, sem código de referência. RÚSSIO, 1979
} 
do museu; objetos culturais, em si ou em réplicas, também escolhidos pela equipe do museu; e objetos resultantes da criatividade infantil, que seriam fruto das atividades de auto-expressão nas mais variadas formas de linguagem e escolhidos pelas próprias crianças.

Os principais objetivos do Museu da Criança seriam: motivar a criança no que tange o processo criador; mostrar o processo de criação como atividade lúcida e consciente do homem, ou seja, como exercício de liberdade; e coletar amostras significativas da criatividade infantil. Já a metodologia de trabalho é descrita pela autora como sendo de "Criação/Fruição" e tendo uma relação especial com a arquitetura. Segundo a proposta, o local deve conquistar e privilegiar a criança, além de ser acessível para as pessoas com deficiência, sendo idealmente um "grande edifício térreo, envolvendo jardins internos e envolvido por área verde" ${ }^{\text {. }}$. Assim, o Museu da Criança se constituiria em um grande serviço educativo, pois estaria integrado em um ambiente que os elementos de trabalho e do espaço museológico corresponderiam às atividades propostas desenvolvidas.

O destino desta proposta, segundo a reportagem "Um Museu da Criança, para a criança" de 12/02/1983 em O Estado de São Paulo teria sido a implantação do Museu nos dois primeiros pisos da FESP, no bairro Pacaembu, na sede do curso de Museologia que Rússio coordenada. Porém, os esforços parecem não terem perdurado e a parceria com Portugal supostamente foi perdida, já que não se tem demais registros da empreitada até o presente momento.

O Museu da Indústria foi um projeto ambicioso que almejava musealizar o processo industrial paulista frente à modernização do país. Rússio o concebia como "museu processo", polinucleado e com várias frentes temáticas. A museóloga chegou a publicar em 1981 uma edição chamada "Um Museu da Indústria em São Paulo"7 na $6^{\circ}$ Coleção Museus \& Técnicas, explanando sobre o plano museológico do projeto, no qual diferenciava as sedes em: museus setoriais e museus de fábrica. Os primeiros contariam a história de um segmento específico e os segundos teriam como objetivo tratar a história da fábrica em questão e a 'área de produção' que se transformaria em museu. ${ }^{8}$

Os documentos pesquisados no arquivo IEB indicam que Waldisa Rússio fora destinada à Secretaria da Indústria Comércio, Ciência e Tecnologia de São Paulo, com o objetivo de coordenar o projeto nomeado Museu da Indústria, Comércio, Ciência e Tecnologia, criado pelo inciso XIII em 17 de abril de 1979. Segundo relatório de $1979^{9}$ fora feito naquele mesmo ano pela equipe de Rússio

\footnotetext{
6 Arquivo IEB - USP, Fundo Waldisa Rússio, sem código de referência. RÚSSIO, 1983.

7 “Um museu para Indústria em São Paulo" foi também o nome de um capítulo da tese de Waldisa Rússio para seu doutoramento na Fundação Escola de Política e Sociologia (FESP).

8 Arquivo IEB - USP, Fundo Waldisa Rússio, sem código de referência. RÚSSIO, 1981.

9 Arquivo IEB - USP, Fundo Waldisa Rússio, sem código de referência.
} 
um levantamento bibliográfico da história da Indústria Brasileira, assim como a realização de anteprojetos, conferências, promoção de estágios e ainda a exposição participatória no Parque da Água Branca com caderno visual e projeto "A fábrica é um Museu".

A exposição participatória mencionada no relatório é um ponto importante para a pesquisa, pois foi uma das aplicações diretas de seu projeto. Chamada de "Oficinas Infantis" do Museu da Indústria, aconteceram em 1979. A atividade escolhida foi a tecelagem, tanto pela importância desta manufatura para a história da industrialização, tanto pela aproximação que a museóloga vinha desenvolvendo com a Fábrica Santa Helena no período. A oficina contou com a prática de exercícios de tear, estamparia, tecelagem e desenho. Consta no mesmo relatório que 21 mil pessoas visitaram a atividade e após o esgotamento dos tecidos disponíveis para a estamparia, as crianças utilizaram suas próprias camisetas para estampar.

Porém, apesar dos inúmeros esforços em sedimentar e viabilizar o projeto do Museu da Indústria, os documentos encontrados até o momento indicam que o projeto tenha sido extinto em 1987. O falecimento precoce de Waldisa Rússio em 1990 contribuiu para que o Museu tenha ficado extinto e esquecido.

A partir do estudo das empreitadas vislumbradas por Waldisa Rússio, a pesquisa dedicou-se a conceber algumas atividades que pudessem ter as práticas museológicas de Waldisa Rússio como inspiração. Foram realizadas ações no Museu Lasar Segall, IEB USP e Ocupação do Ouvidor 63. Para efeito deste texto destaca-se o ateliê no Museu Lasar Segall e na ocupação do Ouvidor 63.

A primeira proposta foi realizada no Museu Lasar Segall, com crianças de 3 e 4 anos, sobre a perspectiva de investigar a criação/fruição proposta por Waldisa Rússio, com referência direta ao Museu da Criança. [figura 1, 2, 3 e 4]

Essa ação nomeada de "Habitáculo" investigou as relações da casa com o corpo, enquanto espaço habitável. Escala, dimensão, tamanho, formas de se entrar e sair e maneiras de se construir abrigos. Estas foram as questões que conduziram a experimentação neste ateliê, no qual a perspectiva de Rússio acerca da criança brasileira foi explorada.

A dinâmica da atividade foi em torno do morar, residir e permanecer. Observou-se que as crianças passaram a separar os cômodos, a determinar a função de cada local e a estabelecer limites e delimitações para cada espaço, propondo autonomia e uma vida cíclica naquele ambiente que passava a ter túneis, curvas e passagens adversas. Ao final, elas contaram terem sentido seus corpos imensos perto das casas e um ritmo de vida próprio naquele local.

Posteriormente foi realizada a ação na Ocupação do Ouvidor 63, juntos aos moradores e ao 


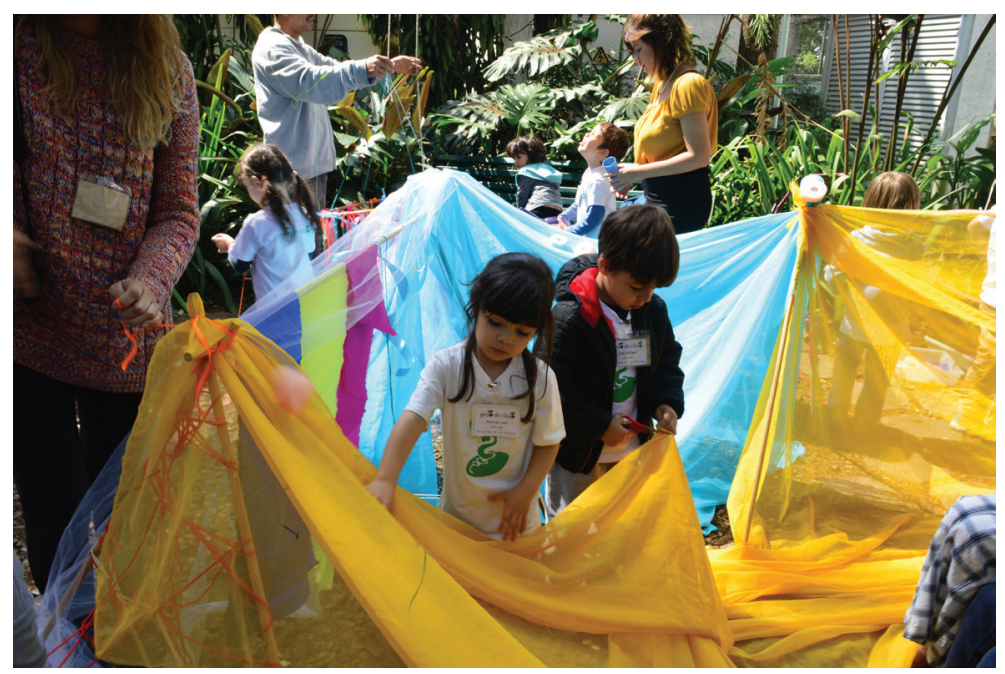

\section{[Figura 1]}

Sophia Novaes. Habitáculo. 2018.

Museu Lasar Segall, São Paulo.

Acervo da autora. Foto: Fernanda Testa.

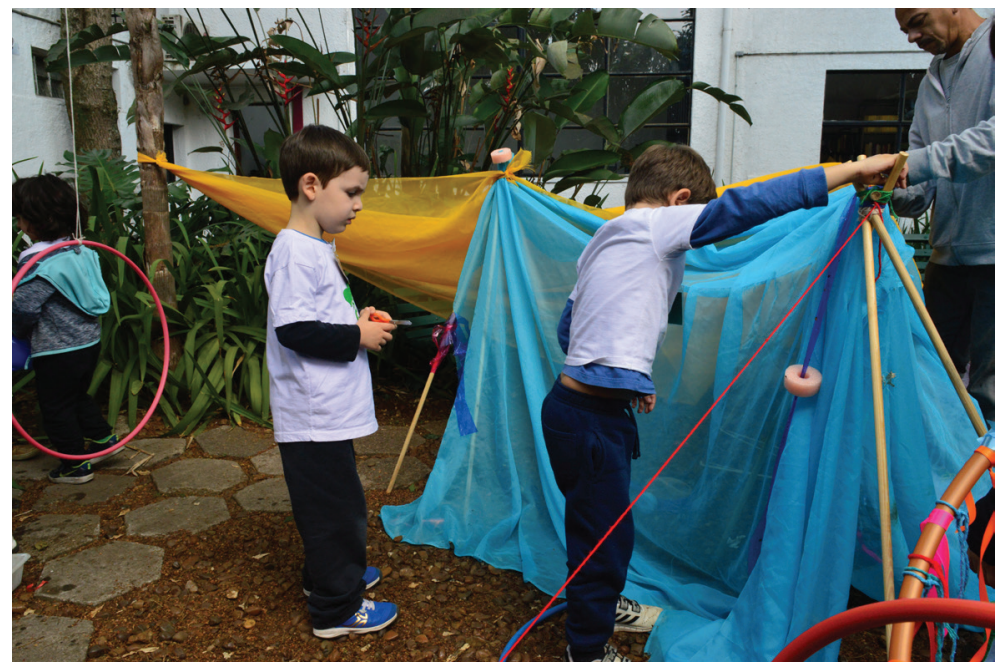

[Figura 3] Sophia Novaes. Habitáculo. 2018. Museu Lasar Segall, São Paulo.

Acervo da autora. Foto: Fernanda Testa.

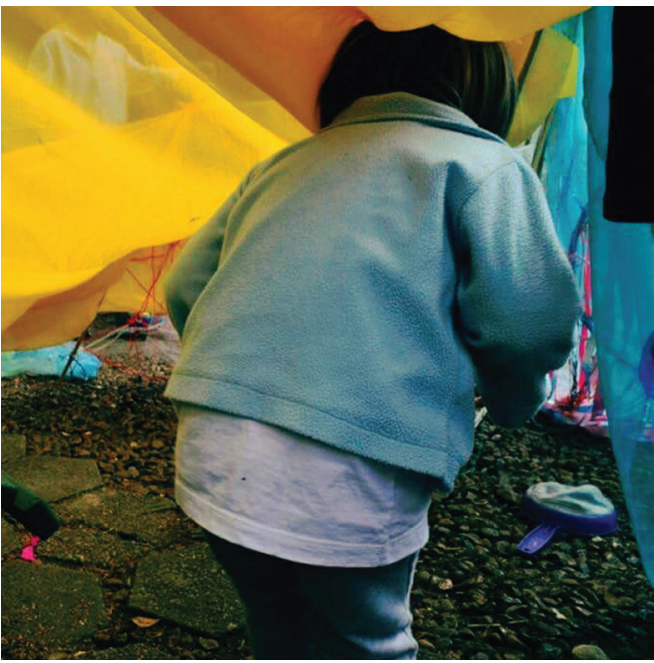

[Figura 2] Sophia Novaes. Habitáculo. 2018. Museu Lasar Segall, São Paulo. Acervo da autora. Foto: Fernanda Testa.

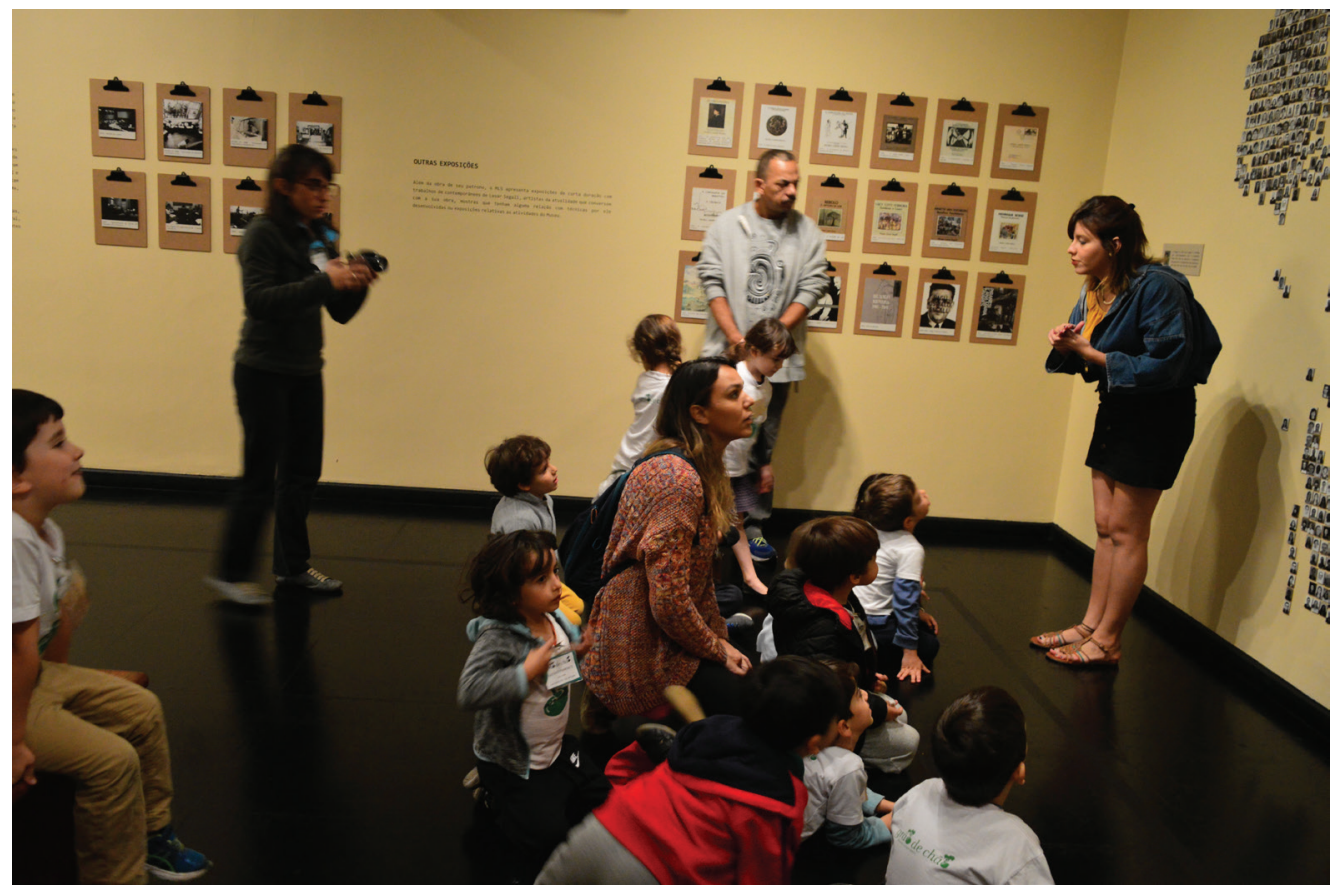

[Figura 4]

Sophia Novaes. Habitáculo. 2018. Museu Lasar Segall, São Paulo.

Acervo da autora. Foto: Fernanda Testa. 
público externo. O local escolhido tem uma importância especial também para a história de Waldisa Rússio. Foi uma das sedes da FESPSP, constando em inúmeros documentos do Fundo Waldisa Rússio. Portanto, o intuito principal do ateliê foi resgatar as propostas comunitárias que Rússio costumava pensar, em especial a chamada "Oficinas do Ouvidor", que fora projetada para aquele exato local, ao passo que também desejava suscitar o olhar para o patrimônio cultural não institucionalizado e em transformação proporcionada pela ocupação. [figura 5, 6, 7 e 8]

A deriva, a observação e o caminhar foram os pontos centrais deste ateliê. A ação se iniciou no quarto andar da Ocupação do Ouvidor, com o convite que todos se vestissem, da maneira que lhe conviesse, os tecidos que foram dispostos. Em seguida, deu-se início uma caminhada pelo centro de São Paulo, onde os participantes poderiam demarcar com pedaços dos tecidos que vestiam, locais ou coisas que chamassem atenção de seu olhar, num despir-se pela cidade.

De volta à Ocupação, o grupo elaborou um mapa tridimensional, no qual podia-se recriar e sinalizar o trajeto que fora feito. Por fim, cada um pôde compartilhar a sensação de caminhar à deriva pelo centro, sem pertences e bolsas, de forma coletiva.

Através dos ateliês realizados pela pesquisa pôde se observar na prática muito do que Waldisa Rússio suscita em seus projetos, especialmente o Museu da Criança e as Oficinas Infantis do Museu da Indústria. Os ambientes de partilha, construídos pelas atividades, foram amparados na vivência com algum objeto (material) e permitiram que de maneira fluída se pudesse pensar sobre a herança cultural pertinente àquele ambiente-espaço, ao mesmo tempo que cada ação produziu respostas ao tempo e momento em que se inserem.

Os três ateliês não visaram ser atividades de desenvolvimento cognitivo, de ação educativa que tem como objetivo a aprendizagem de alguma questão, somente propunham a conexão com aquele ambiente-espaço. Trata-se de 'ser e estar', de forma que somente esta existência já é capaz de gerar identidade e compreensão da herança cultural dos locais em que acontecem.

Esta vivência singular é o principal ponto que a pesquisa extrai dos projetos e das concepções de Waldisa Rússio, pois é possível entender que as práticas de Rússio almejavam este verbo ser/ estar, o experimentar e o partilhar de forma coletiva e autônoma. Desta forma, através dos projetos e propostas de Rússio é possível reconhecer o protagonismo que a autora teve em desenvolver um espaço museal humanizador e intimamente ligado à vida, sendo uma pauta urgente e necessária aos tempos temerosos e atuais do país ainda em desenvolvimento.

A relação profunda do homem com o objeto no cenário do museu - "fato museológico" - é um convite para experimentar estes locais de forma a se criar identidade e se atribuir valor aos vestígios 


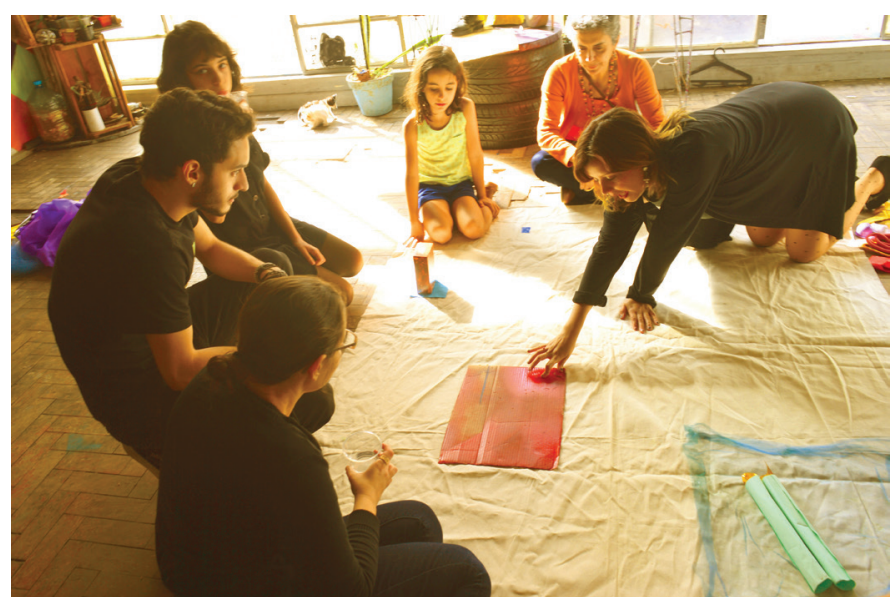

[Figura 5] Sophia Novaes. Museus Democráticos e Obra Aberta. 2018. Ocupação do Ouvidor 63, São Paulo. Acervo da autora. Foto: Fernanda Testa.

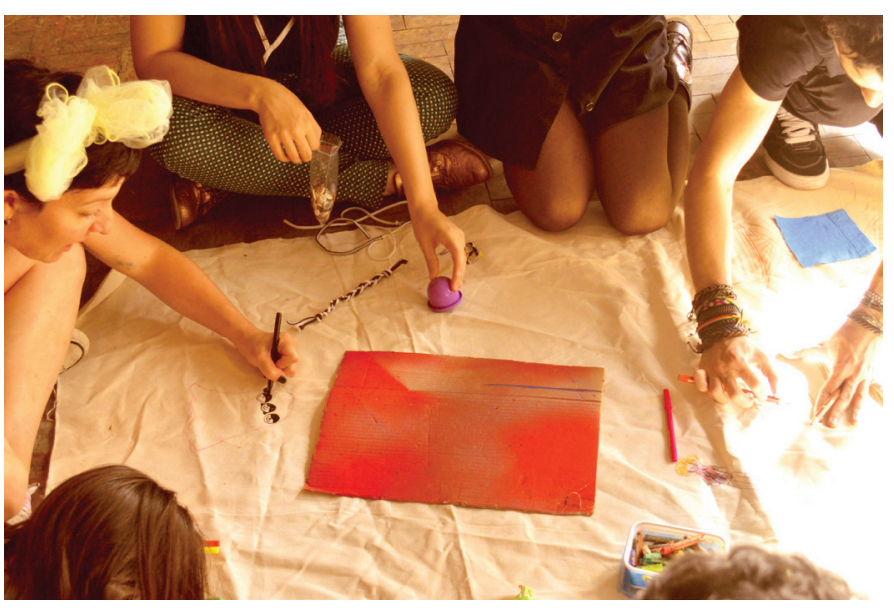

[Figura 6] Sophia Novaes. Museus Democráticos e Obra Aberta. 2018. Ocupação do Ouvidor 63, São Paulo. Acervo da autora. Foto: Fernanda Testa.
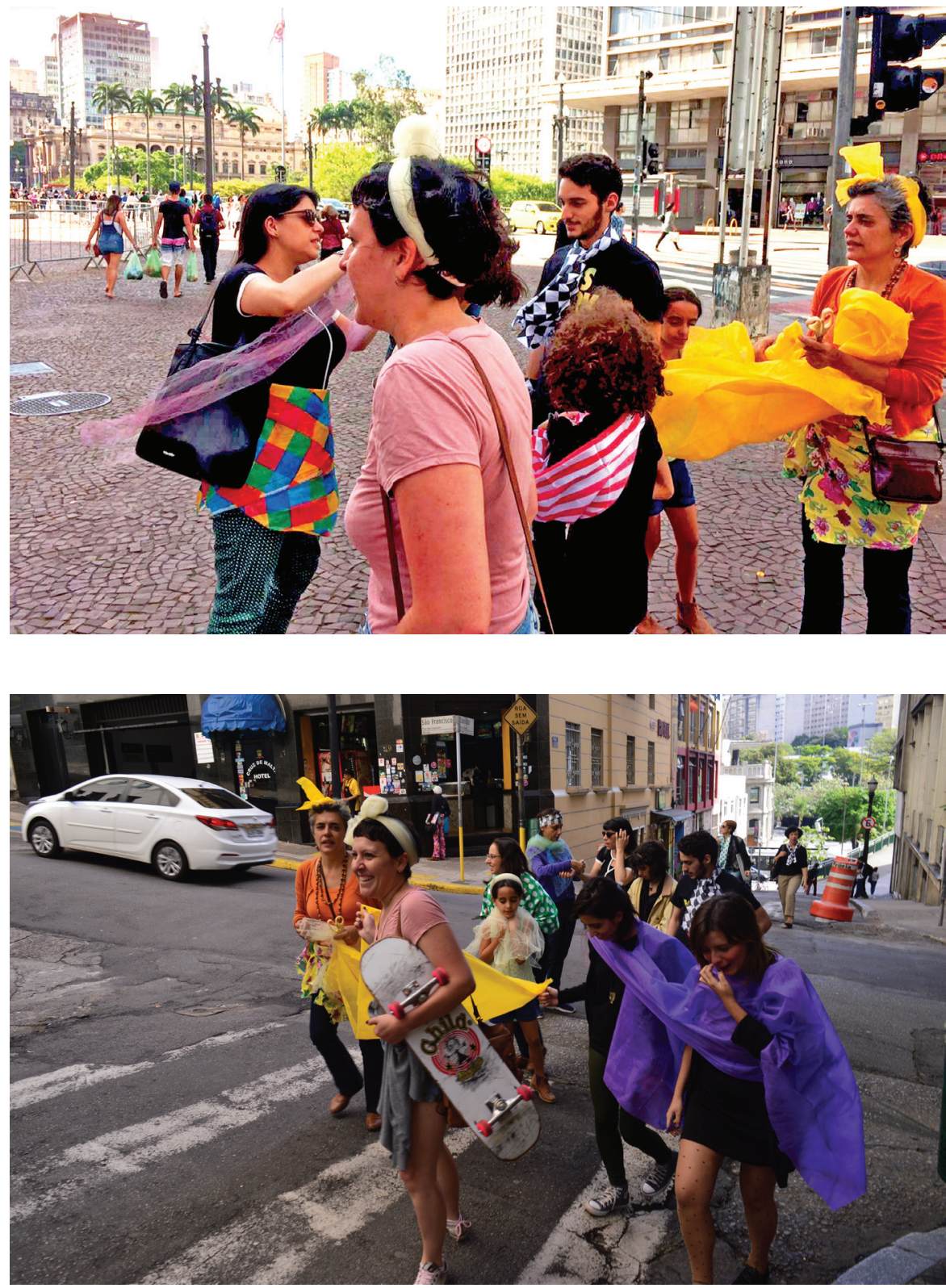

\section{[Figura 7]}

Sophia Novaes. Museus Democráticos e Obra Aberta. 2018. Ocupação do Ouvidor 63, São Paulo.

Acervo da autora. Foto: Fernanda Testa.

\section{[Figura 8]}

Sophia Novaes. Museus Democráticos e Obra Aberta. 2018. Ocupação do Ouvidor 63, São Paulo.

Acervo da autora. Foto: Fernanda Testa. 
culturais. Uma possibilidade de ver, ser visto, ouvir, ser ouvido, e compartilhar a realidade.

Se realmente a Memória não é só o passado mas também o processo, a identidade, construída ao longo da experiência partilhada e vivida, é, também, processo.

É urgente saber o que nos resta como patrimônio cultural e qual é nossa contribuição para esse patrimônio. É urgente conhecer nosso próprio rosto. ${ }^{10}$

Rússio sonhava um futuro para nós e para nosso passado, portanto as pesquisas a respeito do seu legado, suscitam esse sonho. São um meio de trabalho para a construção de ambientes patrimoniais como locais vitais para a atribuição de valor à herança cultural.

As atividades de criação, de manifestação e expressão dos grupos nestes espaços patrimoniais das cidades, como os museus, para Rússio significam a possibilidade de elaborar sistemas de valores que levam em consideração o modo de vida da sociedade, suas referências e linguagens. Por este motivo, é possível notar a importância de seu papel para a trajetória da educação museal no Brasil, como resistência e luta pela herança cultural, fazendo com que seja essencial a continuação do processo de mapeamento, organização e difusão do legado de Waldisa Rússio.

\section{Referências Bibliográficas}

ARAUJO, Marcelo Mattos; BRUNO, Maria Cristina Oliveira (org.) A Memória do Pensamento Museológico Contemporâneo: Documentos e Depoimentos. São Paulo: Comitê Brasileiro do ICOM, 1995.

BRUNO, Maria Cristina Oliveira. Políticas Públicas no Brasil Contemporâneo: qual é o papel dos museus e dos Centros de Memória?. Cadernos Tramas da Memória, v. 1, p. 115-126, 2011.

BRUNO, Maria Cristina Oliveira.(Coord.). Waldisa Rússio Camargo Guarnieri: textos e contextos de uma trajetória profissional. São Paulo: Pinacoteca do Estado, 2010.

CRIMP, D. Sobre as ruínas do museu. São Paulo: Martins Fontes, 2005. [caps."Sobre as ruínas do museu" e "O museu pós-moderno"].

MARIAUX, P. A. (Ed.). L'objet de la muséologie. Neuchâtel: Université de Neuchâtel, Institut d'Histoire de l'Art et de Muséologie, 2005. (Col. L’Atelier de Thesis, n. 2).

MENESES, U. T. B. Do teatro da memória ao laboratório da História: a exposição museológica e o conhecimento histórico. Anais do Museu Paulista, São Paulo, v.2, p. 9-42,1994.

10 Arquivo IEB - USP, Fundo Waldisa Rússio, sem código de referência. RÚSSIO, 1979 